\title{
FLUOROSIS AND THE PARATHYROID GLANDS
}

\author{
By Leo SPIRA, M.D. (Vienna), M.D. (Prague), \\ M.R.C.S. (Eng.), CAPTAIN R.A.M.C.
}

A disease picture frequently observed amongst the population of this country was shown (S.pira, 1933) to be traceable to fluorine, amongst other chemical substances, contained in drinking water and aluminium cooking utensils. The occurrence of ' mottled teeth' should have been included, but it was unfortunately overlooked until a subsequent investigation (Spira, 1942 a,b) revealed the fact that nearly $22 \%$, that is 1099 out of 5019 men and women examined, were afflicted. This was followed by a further inquiry (Spira, $1942 c$ ), amongst those having mottled teeth, into the co-existence of some of the more frequent signs and symptoms which formed part of the disease picture referred to above. The result of this inquiry helped to establish more firmly the symptomatology of chronic fluorine poisoning (fluorosis). It was shown that three main groups of symptoms could be discerned. They comprised disturbances of (1) the gastro-intestinal tract, (2) the peripheral nervous system, and (3) the organs biologically originating in the ectoderm and regulated by the parathyroid glands, that is to say, the teeth, skin, nails and hair.

The object of the present paper is to discuss the work done.in the past in connexion with the third group. The lesions of the skin, nails and hair were found so frequently to accompany the condition known as 'mottled teeth', a hypoplasia caused by the protracted ingestion of toxic amounts of fluorine, that it soon became evident that they too were probably caused by the same toxic agent. Since all these structures are regulated by the parathyroid glands, the conclusion forced itself on my mind that it must be these glands themselves which are affected in some way by fluorine. On further study of the literature on mottled teeth it was found that the same conclusion had been arrived at already, although only in so far as mottled teeth were concerned, by other investigators (Bergara, 1929; Chaneles, 1929; Pavlovic \& Tihomirov, 1932). This limited reference to the correlation of mottled teeth with the disturbed action of the parathyroid glands was based by them on the close similarity of the dental dystrophy with that produced by Erdheim (1906) in his well-known observations on experimental parathyroidectomy in rats. When Erdheim first reported the results of his investigation into the correlation of the parathyroid glands with tetany (Tetania parathyreopriva), he was establishing not only a new conception of parathyroidectomy leading to the development of rickets and osteomalacia as well, but, what for the purpose of our study of fluorosis is of the greatest importance, the fact that it was also the cause of profound dental changes. He was thus able to prove that the parathyroid glands regulated the calcium metabolism, since their removal was followed by both bony and dental changes. The teeth of his experimental rats became white and opaque, lost their normal yellow translucent appearance, increased in length and became brittle and distorted. Immediately after the parathyroidectomy the calcification of the newly formed dentin was either diminished, or ceased altogether. Removal of the parathyroid glands and immediate transplantation into the abdominal wall produced white, opaque, decalcified bands across the incisors of the experimental 
rats. These dental findings proved to be of sufficient importance to be taken up by several investigators for further study. Hammett (1922), Korenchevsky (1922), Hohlbaum (1911) and Izumi (1920), all confirmed the dental findings of Erdheim. In a large series of experiments on rats Toyofuku (1911) found defects and erosions in the dentin. As a result of a poorly calcified dentin the teeth became loose, and assumed an undulated appearance. Some of the teeth became black, and a few of the erosions showed a dark discoloration. There was in several instances suppuration in the alveoli of the incisors.

Thus with a few exceptions, due to morphological differences between the teeth of rat and man, the changes produced by parathyroidectomy are similar to those known in man as mottled teeth. For this reason, and also because it has been dealt with at great length by several writers in different countries, a further description of mottled teeth, as seen in man, can now be omitted, and readers referred to the literature. It should only be noted that since, so far as can be ascertained, the first recorded mention of dental changes, later to be known as mottled teeth, was made by Eager (1902), fully 30 years elapsed before Smith, Lantz \& Smith (1932) established the fact that it was the fluorine contained in the drinking water in a concentration of more than 1 part per million which was the aetiological factor producing the lesion. This was the culmination of patient and persistent work done mainly by American investigators in their endeavour to find the baffling cause of the unsightly appearance of the teeth. The result was the more outstanding as nothing was at that time known of any other signs and symptoms which may accompany this dental dystrophy.

Nor, at the time of my clinical study of the symptom complex above referred to, did I know anything either of the dental changes produced by Erdheim in his experimental parathyroidectomy or of the changes traced by the American investigators to chronic fluorine poisoning. Paraesthesiae affecting the area supplied by the ulnar nerve were, however, so striking a feature amongst those symptoms that, in view of the well-known fact that there is only one poison which affects the ulnar nerve, just as lead affects the radial nerve, namely, fluorine, these paraesthesiae were, on clinical grounds alone, together with several other signs and symptoms, attributed by me to fluorosis. Outstanding amongst these were various dermatoses, dystrophies of the finger- and toe-nails, and loss of hair. The affections of the skin and those of the nails yielded to none of the many methods of local treatment, but disappeared promptly when the sources of fluorosis were cut off and the poison accumulated in the body was eliminated by means of an effective adsorbent (charcoal) and an aperient. The cutaneous manifestations of fluorosis included recurrent attacks of acute and chronic urticaria, furunculosis, so-called 'dhobiitch', cheiropompholyx and dysidrosis. The dystrophy of the finger- and toe-nails was shown (Spira, 1942 d) to resemble the condition known as ' mottled teeth' to such an extent as to justify the use of the term 'mottled nails'. In connexion with this finding, never before recorded, it should be noted that Hauck, Steenbock \& Parsons (1933a) noticed that the nails of rats, particularly those of the hind paws, became very long when fluorine was fed experimentally for several months. It was pointed out (Spira, 1928, 1933, 1942c) that the hair too was found to undergo changes characterized by its falling out at an unusually early age. Some of the victims of alopecia, which on occasions even led to complete baldness, stated that they lost their hair within a fortnight, without this condition being attributed to any apparent reason; others connected it with some digestive trouble of obscure origin and of only a few weeks' duration. It remains to be 
seen whether the loss of hair is in such cases due to the involvement of the skin or of the hair follicles. It was, however, observed that not only did the hair fall out in bulk, but that the hairs which still remained broke easily. The nett result of such brittleness of the hair was that it hardly seemed to grow.

It is thus seen that the clinical observation of the changes in the skin, teeth, nails and hair could not but lead inevitably to the conclusion that it was a case not of each of these structures being affected in turn primarily by fluorine, but of their all being affected secondarily through the organs regulating their function, i.e. the parathyroid glands. This conclusion arrived at independently through clinical investigation alone, without the knowledge of, and therefore uninfluenced by, any contradictory views expressed on the subject by earlier workers, thus adds weight to the arguments in favour of a similar conclusion arrived at through different channels of investigation. The first intimation that there might be a relationship between mottled teeth and a disturbance of the endocrine glands appears to have been given by McKay (1918). In a discussion on mottled teeth recorded in the Journal of the American Medical Association $(1936,107,1269)$ Bristol suggested that there might be a correlation between the mottling of the enamel and what is popularly called 'mottling of the skin', and Dean (1936) quoted Black \& McKay (1916) who found that mottled teeth were pronounced in children predisposed to freckling, and Lemmon as stating that they occur more frequently in blonds and 'red heads'. Chaneles (1929b) expressed the belief that the organs regulating the calcium metabolism are affected by fluorine, even in apparently harmless quantities. Pavlovic \& Tihomirov (1932) found the parathyroid glands in experimental fluorosis to be pale. Histologically the cells were found to stain badly, the protoplasm was diminished in amount in comparison with normal cells, and the nuclei also stained badly and contained vacuoles. A slight general hyperaemia, and in some instances haemorrhages were found. In addition, the endothelium stained badly. The anatomical changes were indicative of a state of fatty degeneration.

Hauck et al. (1933a) found several structural variations in the parathyroid glands of rats with experimental fluorosis. The cell nuclei were smaller and more chromatic than normal. There was an increase in the connective tissue stroma in some of the glands, greater vascularity, pyknotic nuclei in vacuolated cells, and areas of apparent fatty degeneration. In spite of these findings they thought that there was no abnormality present to a degree sufficient to suggest interference with functional activity of the glands as a whole. For this reason they came to the conclusion that there was 'no evidence that the parathyroid glands in the rat undergo any significant change, either grossly or microscopically, with the administration of toxic doses of sodium fluoride. Therefore the explanation for the apparently identical dental effects produced by sodium fluoride administration and parathyroidectomy must be sought in some other mechanism, unless in this respect anatomical criteria are of no value.'

Sutro (1935) expressed the belief that the changes in the teeth and bones of rats to which sodium fluoride was administered are due principally to a chemical disturbance which is unrelated to the parathyroid glands, since subcutaneous injections of parathyroid extract, given up to a total of .700 units over a period of 2-3 months, neither retarded nor prevented the appearance of mottled teeth.

In addition to the identity of the dental changes produced by Erdheim's parathyroidectomy on the one hand, and by fluorine on the other, certain other signs and symptoms are common to both these conditions (cf. Erdheim, 1906, 1911; Spira, 1933, 1942b), and 
thus strengthen still further the conclusion that fluorine exerts a direct effect on the parathyroid glands. Erdheim draws attention to the occurrence of trophic changes in the teeth, nails and hair as belonging to the picture of tetany in man. As a result of parathyroidectomy, however, certain additional features were observed by him in rats; they remain as much beyond dispute as do the dental changes. Outstanding amongst them is the loss of hair. His observations have since been confirmed by Adler \& Thaler. Furthermore, the continuous violent scratching of their snouts and heads, for which not the slightest reason could be detected locally, pointed the occurrence of paraesthesiae in some of the experimental rats. Wagner, Drobnik, Rouxeau, and Vassale are investigators quoted by Erdheim as having since interpreted the pruritus which occurs without any visible cutaneous changes following parathyroidectomy, as caused by paraesthesiae. The tonic spastic contractions of the extremities in parathyroidectomized rats produced such an intense pain as to cause the animals often to express it by a loud cry and by approximating the affected extremity to the mouth, so as to be able to lick it. Erdheim emphasizes the fact that, in general, the condition produced by parathyroidectomy showed a chronic course, and that the effect of the operation was not the same in different individuals. Not all the rats exhibited the same degree of response, although anatomically identical changes were found in all of them.

\section{SUMmary}

There is a close similarity between the dental changes produced experimentally in the rat by parathyroidectomy and mottled teeth as seen in man and known to be caused by protracted ingestion of toxic amounts of fluorine. In view of the fact that both parathyroidectomy and fluorine produce dystrophies in tissues regulated by the parathyroid glands it is concluded that, in man, mottled teeth, certain dermatoses, mottled nails and alopecia may be due to a disturbance of these glands brought about by the ingestion of toxic amounts of fluorine in drinking water.

\section{REFERENCES}

Adler \& Thaler. Cited by Erdherm (1906).

BaUer, T. (1911). Frankfurt. Z. Path. 7, 231.

Bergara, C. (1929). Rev. odontol. 9, 802. Cited by Sutro (1935).

Black, G. V. \& McKay, F. S. (1916). Dent. Cosmos, 58, 129, 477, 627, 781, 894.

Chaneles, J. (1929a). C.R. Soc. Biol., Paris, 102, 860, 863.

Chaneles, J. (1929b). Rev. Soc. argent. Biol. 5, 317, 336, 340, 352, 376, 386.

Dean, H. T. (1936). J. Amer. Med. Ass. 107, 1269.

De Eds, F. (1933). Medicine, 12, 1.

EAGer, J. M. (1902). Dent. Cosmos, 44, 300.

ERdheim, J. (1906). Mitt. Grenzgeb. Med. Chir. 16, 632.

ERdheim, J. (1911). Frankfurt. Z. Path. 7, 175, 238, 295.

Hammett, F. S. (1922). Amer. J. Physiol. 62, 197.

Hauck, H. M., Steenbock, H. \& Parsons, H. T. (1933a). Amer. J. Physiol. 103, 480.

Hauck, H. M., Steenbock, H. \& Parsons, H. T. (1933b). Amer. J. Physiol. 103, 489.

Hohlbaum (1911). Cited by Korenchevsky (1922).

IzUmi (1920). Cited by Korenchevsky (1922). 
Korenchevsky, V. (1922). J. Path. Bact. 25, 366.

McClure, F. J. (1933). Physiol. Rev. 13, 277.

McClure, F. J. \& Mrtchell, H. H. (1931). J. Biol. Chem. 90, 297.

McKay, F. S. (1918). J. Nat. Dent. Ass. 5, 721.

Pavlovic, R. A. \& Bogdanovic, S. B. (1932). C.R. Soc. Biol., Paris, 109, 475.

Pavlovic, R. A. \& Trhomirov, D. M. (1932). C.R. Soc. Biol., Paris, 110, 497.

Smith, M. C., Lantz, E. \& Smith, H. V. (1932). J. Dent. Res. $12,149$.

Sollman, T., Schettler, O. H. \& Wetzel, N. C. (1921). J. Pharmacol. 17, 197.

SpIRA, L. (1928). Franco-Brit. Med. Rev. 5, 1, 61.

SpIra, L. (1933). The Clinical Aspect of Chronic Poisoning by Aluminium and its Alloys. London: John Bale, Sons and Danielsson.

SPIRA, L. (1942a). Lancet, 1, 649.

SPIRA, L. (1942b). Brit. dent. J. 73, 148.

SPIRA, L. (1942c). J. Hyg., Camb. (in the Press).

SPIRA, L. (1942d). Edinb. Med. J. (in the Press).

Sutro, C. J. (1935). Arch. Path. 19, 159.

Toyofuko, T. (1911). Frankfurt. Z. Path. 7, 249.

WIIson, R. H. \& DE EDs, F. (1940). Endocrinol. 26, 851.

(MS. received for publication 22. vII. 42.-Ed.) 